\title{
Proteins are the major players in the formation of staphylococcus aureus biofilms
}

\author{
Volume 4 Issue 2 - 2017 \\ Yeswanth S, Sarma PVGK \\ Department of Biotechnology, India
}

\begin{abstract}
Keywords: staphylococcus aureus,biofilms, immune, phosphorylation, signaling, planktonic, hemophilic, heterophilic, viscoelastic, stabilization, maturation
\end{abstract}

\section{Short communication}

The virulence capacity of Staphylococcus aureus increases many folds with the formation of biofilms and in this state it can cause persistent infections and they exhibit resistance to antibiotics and host immune system. ${ }^{1}$ Biofilms comprises of either homogenous or mixed populations of microbes, that are formed initially as planktonic bacteria which reversibly attach to a surface irreversibly leading to the formation of small colonies on the surface. With the aid of quorum sensing and other signalling events such as phosphorylation, maturation and stabilization of biofilms occur. Thereafter, microbes inside the biofilm disperse with the help of surface proteins and releases bacteria residing on the top of biofilm structure and thus it spreads in the host. ${ }^{2}$ These interactions of surface anchored proteins are both homophilic and heterophilic in nature which are largely through surfactant peptides one of the key players in the formation of biofilms and gives viscoelastic behaviour.,

Adhesion is the primary step in the biofilm formation which is facilitated by the expression of microbial surface components which recognize adhesive matrix molecules (MSCRAMMs). These MSCRAMMs can bind to host extracellular matrix components ${ }^{5,6}$ and share a general signal sequence for secretion and as well as for anchoring to the cell wall. ${ }^{7}$ MSCRAMMs have to be introduced from the inner part of the bacteria followed by successive attachment to the bacterial surface, this process involves the sec pathway and the sortase thus playing a essential role in $S$. aureus pathogenesis. ${ }^{8,9}$

Studies have shown that surface-anchored proteins promote biofilm formation in $S$. aureus, which includes IgG-binding protein Protein-A, Fibronectin binding protein-A (FnbA), surface-associated proteins $\mathrm{SasC}$ and $\mathrm{SasG},{ }^{6,10-13}$ and biofilm-associated protein Bap. ${ }^{14}$ Under low iron conditions secreted proteins Emp and Eap are implicated in biofilm formation. ${ }^{6} \mathrm{SpA}$ and $\mathrm{FnbA}$ are directly associated with biofilm formation in all the growth conditions of $S$. aureus and constitute the major biofilm forming proteins. Further, $\mathrm{SpA}$ gene deletion experiments or blocking the Protein-A by adding human serum has shown biofilm formation was completely abolished indicating essential role played by Protein-A in the formation of biofilms. ${ }^{7,15-18}$ The involvement of proteins in general and SpA and FnbA in particular confirmed by the over expression of Rsp a transcription regulator and proteolytic enzyme ${ }^{6}$ in aerobic conditions where high oxidative conditions promote large catabolic activities and poor biofilm formation.

\section{Acknowledgments}

None.

\author{
Correspondence: Sarma PVGK, Department of Biotechnology, \\ SriVenkateswara Institute of Medical Sciences and University, \\ Tirupati-5 17507, India, Tel 9.18772E+ II, \\ Emailsarmasvims@gmail.com
}

Received: February 15, 2017 | Published: February 20, 2017

\section{Conflicts of interest}

Author declares there are no conflicts of interest.

\section{Funding}

None.

\section{References}

1. O’Neill E, Pozzi C, Houston P, et al. A novel Staphylococcus aureus biofilm phenotype mediated by the fibronectin binding proteins, FnBPA and Fn- BPB. J Bacteriol. 190(11):3835-3850.

2. Cortes ME, Consuegra J, Sinisterra RD. Biofilm formation, control and novel strategies for eradication. Science Against Microbial Pathogens: Communcating Current Research Technological Advances. 2011;2:896-905.

3. Stoodley P, Sauer K, Davies DG, et al. Biofilms as complex differentiated communities. Annu Rev Microbiol. 2002;56(1):187-209.

4. Gupta P, Sarkar S, Das B, et al. Biofilm, pathogenesis and prevention-a journey to break the wall: a review. Arch Microbiol. 2016;198(1):1-15.

5. Gotz F. Staphylococcus and biofilms. Mol Microbiol. 2002;43(6):1367-1378.

6. Cramton SE, Gerke C, Schnell NF, et al. The intercellular adhesion (ica) locus is present in Staphylococcus aureus and is required for biofilm formation. Infect Immun. 1999;67(10):5427-5433.

7. Lei MG, Cue D, Roux CM, et al. Rsp Inhibits Attachment and Biofilm Formation by Repressing fnbA in Staphylococcus aureus MW2. J Bacteriol. 2011;193(19):5231-5241.

8. Fitzpatrick F, Humphreys H, O'Gara JP. Evidence for icaADBCindependent biofilm development mechanism in methicillinresistant Staphylococcus aureus clinical isolates. J Clin Microbiol. 2005;43(4):1973-1976.

9. Corrigan RM, Rigby D, Handley P, et al. The role of Staphylococcus aureus surface protein SasG in adherence and biofilm formation. Microbiology. 2007;153(8):2435-2446. 
10. Cucarella C, Solano C, Valle J, et al. Bap, a Staphylococcus aureus surface protein involved in biofilm formation. $J$ Bacteriol. 2001;183(9):2888-2896.

11. Merino N, Arana AT, Irigaray VM, et al. Protein A-mediated multicellular behavior in Staphylococcus aureus. J Bacteriol . 2009;191(3):832-843.

12. Schroeder K, Jularic M, Horsburgh SM, et al. Molecular characterization of a novel Staphylococcus aureus surface protein (SasC) involved in cell aggregation and biofilm accumulation. PLoS One. 2009;4(10):e7567.

13. Irigaray VM, Valle $\mathrm{J}$, Merino $\mathrm{N}$, et al. Relevant role of fibronectinbinding proteins in Staphylococcus aureus biofilm associated foreignbody infections. Infect Immun. 2009;77(9):3978-3991.

14. Deisenhofer J. Crystallographic refinement and atomic models of a human Fc fragment and its complex with fragment B of protein A from Staphylococcus aureus at 2.9- and 2.8 resolution. Biochemistry. 1981;20(9):2361-2370.
15. Cedergren L, Andersson R, Jansson B, et al. Mutational analysis of the interaction between staphylococcal protein A and human IgG1. Protein Eng. 1993;6(4):441-448.

16. Smith EJ, Corrigan RM, van der Sluis T, et al. The immune evasion protein Sbi of Staphylococcus aureus occurs both extracellularly and anchored to the cell envelope by binding lipoteichoic acid. Mol Microbiol. 2012;83(4):789-804.

17. Burman JD, Leung E, Atkins KL, et al. Interaction of human complement with Sbi, a staphylococcal immunoglobulin-binding protein: indications of a novel mechanism of complement evasion by Staphylococcusaureus. J Biol Chem. 2008;283(25):17579-17593.

18. Archer NK, Mazaitis MJ, Costerton JW, et al. Staphylococcus aureusbiofilms properties, regulation and roles in human disease. Virulence. 2011;2(5):445-459. 